\title{
Ion-exchange properties of solid solutions based on hydrated forms of monovalent metals antimonate-tungstates
}

\author{
(C) Olga A. Firsova, Elena M. Filonenko, Yulia A. Lupitskaya, ${ }^{{ }^{+}}$ \\ Hurshid N. Bozorov, and Anatoly V. Butakov \\ Department of Condensed Matter Physics. Chelyabinsk State University. \\ Bratiev Kashirinyh St., 129. Chelyabinsk, 454001. Russia. \\ Phone: 8-908-056-32-92. E-mail: lupitskaya@gmail.com
}

\begin{abstract}
*Supervising author; ${ }^{+}$Corresponding author
Keywords: tungsten-antimony acid, solid solutions, pyrochlore-type structure, ion-exchange properties.
\end{abstract}

\section{Abstract}

The research of tungsten-antimony crystalline acid (TACA) structural transformations in the condition of ion-exchange and thermolysis of its substituted $\mathrm{M}^{+}, \mathrm{H}^{+}$-forms $\left(\mathrm{M}^{+}-\mathrm{Li}, \mathrm{Na}, \mathrm{K}, \mathrm{Ag}\right)$ were conducted. The data of thermogravimetric and qualitative X-ray phase analyses made it possible to conclude that the thermolysis of TACA and its derivatives proceeds in a wide temperature range from 300 to $1150 \mathrm{~K}$ being accompanied by the removal of crystalline water molecules with the formation of phases mixture containing complex antimony oxides of the $\left(\alpha-, \beta-\mathrm{Sb}_{2} \mathrm{O}_{4}\right)$ modification and $\mathrm{WO}_{3}$. It was shown that compounds based on hydrated forms of monovalent metal antimonates-tungstates are stable up to $1023 \mathrm{~K}$ with a pyrochlore-type structure. For pyrochlore-like phases, a monotonic dependence of unit cell parameter $a$ on ion-exchange degree $\alpha$ and the ionic radius of metals $r$ was revealed indicating the formation of solid solutions $\mathrm{M}_{x}\left(\mathrm{H}_{3} \mathrm{O}\right)_{1-x} \mathrm{WSbO}_{6} \mathrm{nH}_{2} \mathrm{O}\left(\mathrm{M}^{+}-\mathrm{Li}, \mathrm{Na}, \mathrm{K}, \mathrm{Ag} ; 0.0 \leq x<1.0 ; 0.0 \leq n<2.0\right)$ with a limited range of solubility from the crystal chemistry point of view. Within the framework of the Fd-3m space group, based on the data of X-ray diffraction analysis (Rietveld method), the structural characteristics of TACA and its substituted $\mathrm{M}^{+}, \mathrm{H}^{+}$-forms were refined, and a model for populating the corresponding metal ions by crystallographic positions of the pyrochlore-type structure was proposed. Using a complex of physicochemical methods (thermogravimetric, X-ray diffraction analyses and IR spectroscopy), a correlation between the composition of the obtained compounds, structural disorder, and ion-exchange properties were determined. According to the data of thermogravimetry and IR spectroscopy, it follows that the degree of compounds hydration analyzed depends on the nature of the alkaline ion. This allows to conclude that lithium and sodium ions are located in $16 d$-positions, dragging neutral water molecules into the structure occupying $8 b$-positions. In this case, potassium ions can partially occupy both $16 d$ - and $8 b$-positions of the structure.

\section{References}

[1] A.B. Yaroslavtsev, Yu.A. Dobrovolsky, N.S. Shaglaeva, L.A. Frolova, E.V. Gerasimova, E.A. Sanginov. Nanostructured materials for low-temperature fuel cells. Russ. Chem. Rev. 2012. Vol.81. No.3. P.191220. (russian)

[2] S. Nikodemski, J. Tong, R. O'Hayre. Solid-state reactive sintering mechanism for proton conducting ceramics. J. Solid State Ionics. 2013. Vol.253. P.201-210.

[3] Yu.A. Lupitskaya, D.A. Kalganov, L.Yu. Kovalenko, F.A. Yaroshenko, Yu.V. Antonova. Phase formation, structure and ion conductivity of silver antimonate-molibdats. Vestn. Yuzhno-Ural. Gos. Unta. Ser. Matem. Mekh. Fiz. 2019. Vol.11. No.2. P.65-70.

[4] M.S. Shchelkanova, M.I. Pantyukhina, E.G. Vovkotrub, and S.V. Plaksin. Interrelation of transport properties and dynamics of fluctuation of atoms of a crystal lattice of the $\mathrm{Li}_{8-\mathrm{x}} \mathrm{Zr}_{1-\mathrm{x}} \mathrm{V}_{\mathrm{x}} \mathrm{O}_{6}$ solid solutions. Butlerov Communications. 2015. Vol.44. No.12. P.132-136. DOI: 10.37952/ROI-jbc-01/15-44-12-132

[5] O.A. Mezhenina, V.A. Burmistrov, A.A. Biryukova. Structure and ion-exchange properties of crystalline tungstoantimonic acid. Inorganic Materials. 2015. Vol.51. No.2. P.167-171.

[6] I.A. Stenina, A.B. Yaroslavtsev. Low- and intermediate-temperature proton-conducting electrolytes. Inorganic Materials. 2017. Vol.53. No.3. P.241-251. (russian)

[7] L.Yu. Kovalenko, V.A. Burmistrov, Yu.A. Lupitskaya, I.N. Kovalev, and D.M. Galimov. Synthesis of the solid solutions $\mathrm{H}_{2} \mathrm{Sb}_{2-\mathrm{x}} \mathrm{V}_{\mathrm{x}} \mathrm{O}_{6} \cdot \mathrm{nH}_{2} \mathrm{O}$ with the pyrochlore-type structure. Butlerov Communications. 2018. Vol.55. No.8. P.24-30. DOI: 10.37952/ROI-jbc-01/18-55-8-24

[8] L.Yu. Kovalenko, F.A. Yaroshenko, V.A. Burmistrov, T.N. Isaeva, D.M. Galimov. Thermolysis of Hydrated Antimony Pentoxide. Inorganic Materials. 2019. Vol.55. No.6. P.586-592. 